\title{
PREVALENCE OF CLINICAL MANIFESTATIONS AND ORTHOPEDIC ALTERATIONS IN PATIENTS WITH LIPEDEMA: A PROSPECTIVE COHORT STUDY
}

\author{
I. Forner-Cordero, M.V. Pérez-Pomares, Á. Forner, \\ A.B Ponce-Garrido, J. Muñoz-Langa
}

Lymphedema Unit (IF-C), Physical Medicine and Rehabilitation Service. Hospital Universitari i Politècnic La Fe, University of Valencia, Valencia; Brain Damage Unit (MVP-P), Physical Medicine and Rehabilitation Service, Hospital La Pedrera de Dénia; Physical Medicine and Rehabilitation Service (AF), Sagunto Hospital, University of Valencia, Valencia; Physical Medicine and Rehabilitation Service (ABP-G), Hospital Universitario de Albacete; and Medical Oncology Department (JM-L), Hospital Clínico Universitario de Valencia, Valencia, Spain

\section{ABSTRACT}

Lipedema is a chronic disease seen frequently in women that causes abnormal fat deposition in the lower limbs and associated bruising and pain. Despite increasing knowledge concerning lipedema, there are still aspects of diagnosis that need further investigation. We performed a prospective, observational cohort study to describe prevalence of clinical characteristics present in patients with lipedema in an attempt to establish diagnostic criteria. Participants were consecutive patients with lipedema presenting at a public hospital in Spain from September 2012 to December 2019. Patients were examined for the following signs and symptoms of lipedema: symmetrical involvement; disproportion between the upper and lower part of the body; sparing of the feet; pain; bruising; Stemmer' sign; pitting test; fibrosis; venous insufficiency; upper limbs involvement; vascular spiders; skin coldness; and lymphangitis attacks. In addition, orthopedic alterations were examined in all patients. We recruited 138 patients (median age $=47.6$ years; mean $\left.B M I=29.9 \mathrm{Kg} / \mathrm{m}^{2}\right)$. Using waist-to-height-ratio, $41.3 \%$ of the patients were slim or healthy. The most frequent type of lipedema was Type III
(71\%), and most were in stage 1 and 2.

The features of lipedema with a prevalence $>80 \%$ were symmetrical involvement, unaffected feet, pain, bruising, vascular spiders, and disproportion. Pain was nociceptive in $60.2 \%$ and neuropathic in $33.1 \%$, and there was a reduced social or working activities in 37.9\%. Orthopedic alterations including cavusfeet or valgus-knees were observed in $1 / 3$ of the patients. $X$-ray of the knees was performed in 63 patients and knee osteoarthritis diagnosed in 37. We found that the most frequent manifestations of lipedema were bilateral involvement, unaffected feet, pain, easy bruising, vascular spiders, and disproportion between the upper and lower parts of the body. These should be considered as major criteria for diagnosis. In addition, our findings on the prevalence of orthopedic alterations in patients with lipedema highlights the need for a multidisciplinary and integrated approach.

Keywords: lipedema, diagnosis, pain, orthopedic alterations, obesity

Lipedema was first described by Allen and Hines in 1940 (1). It is a chronic disease that is estimated to affect $0.06 \%$ to $10.00 \%$ of 
women (2) presenting as abnormal fat deposition in their lower limbs that is associated with bruising and pain (3). Patients also complain of swelling that begins frequently during puberty and increases with weight gain (4).

Lipedema is often misdiagnosed and poorly investigated with fewer older publications devoted to this disease and only more recently an increased interest and publications. Nevertheless, it is very common and has immense psychological impact. Patients often feel rejected by medical staff, especially when they are stigmatized as being simply "obese." The abundance of synonyms to refer to this condition indicates how little is known about this syndrome (e.g., adipositas dolorosa, lipomatosis dolorosa, painful lipohipertrophy) (5). This condition is known to cause remarkable psychological, social and physical implications for patients' quality of life (6).

Despite its high prevalence in the female population, the World Health Organization had not included it as a disease until 2018. Lipedema is now classified in the International Classification of Diseases (ICD) as "EF02 Certain non-inflammatory disorders of subcutaneous fat" (7). In recent years, both basic and clinical research have increased all over the world and new management guidelines have been published. But efforts are still needed to increase the visibility of lipedema and the awareness among professionals to help patients get an early and precise diagnosis and an accurate management (8).

Despite the increasing knowledge about lipedema, there are still several aspects of diagnosis that need to be addressed. The first one is diagnostic criteria because a diagnosis of certainty is the basis of any inclusion criteria for any research. Wold et al described diagnostic criteria in 1951 (9), and this has been modified by Herbst (10): almost exclusive occurrence in women; bilateral and symmetrical nature with minimal involvement of the feet; minimal pitting edema; pain, tenderness, and easy bruising; persistent enlargement despite elevation of the extremities or weight loss; increased vascular fragility; and easy bruising. The accuracy of these criteria cannot be assessed as we lack a gold-standard test. In ad- dition, the prevalence of clinical manifestations of lipedema and orthopedic alterations is still unknown.

The main objective of this study is to describe the prevalence of the clinical characteristics present in patients with lipedema to develop an ordinal system of diagnostic criteria. The secondary objective is to assess and analyze if orthopedic alterations are present or not in these patients.

\section{METHODS}

\section{Study Design}

Study was a prospective, non-interventional, cohort design that identified characteristics of patients with lipedema. Lipedema was defined as patients with lower limb enlargement with edema and fat deposition and a disproportion between the upper and lower part of the body. Cases were recruited prospectively and consecutively to avoid selection bias. Selected data were recorded from the patients' clinical records in the electronic Case Report Form (eCRF). Prior to inclusion in the study, patients received information about the study and after clarifying any questions, they signed an informed consent form. The study was approved by the Research Ethics Committee of University and Polytechnic Hospital La Fe (number 2014/0099).

\section{Study Population}

Consecutive female patients with a diagnosis of swelling at the lower limbs who present at the Lymphedema Unit of the University Hospital La Fe, were screened by investigators and checked for eligibility. Eligibility criteria include being $>18$ years of age with bilateral lower limb enlargement and at least 3 symptoms of lipedema: spontaneous or provoked pain or tenderness, easy bruising, family history of lipedema, absence of lower limb injuries, absence of Stemmer sign, symmetrical involvement of the lower limbs, no swollen feet. Pregnancy, renal, hepatic, or heart failure, thrombosis, infection, active cancer and corticosteroid treatment were exclusion 
criteria. Lack or withdrawal of patient consent also was a criterion for exclusion.

\section{Study Variables and Objectives}

Two types of variables were collected in the study: general and specific. For all patients, general variables collected included demographic and basic clinical characteristics [date of birth, general health status, weight, height, body mass index (BMI) etc.]. Specific variables included presence of symptoms and signs related to lipedema: bilateral and symmetrical involvement; disproportion between the upper and lower part of the body; sparing of the feet; pain, bruising; Stemmer' sign; pitting test; fibrosis; venous insufficiency; upper limb involvement, vascular spiders; skin coldness; lymphangitis attacks; volume of the limbs; and type and intensity of pain and its interference in daily activity.

Volumes of the lower limbs were calculated using tape perimeter measurements $(C)$ taken from the dorsum of the foot $\left(\mathrm{C}_{1}\right)$ and repeated for every $4 \mathrm{~cm}$ proximally until the root of the limb $\left(C_{n}\right)$, using the Kuhnke formula (11): Volume $=\left(\mathrm{C1}^{2}+\mathrm{C}^{2} 2^{+} \ldots \mathrm{Cn}^{2}\right) / \Pi$.

Lipedema was classified based on localization of the fat accumulation and the severity of clinical manifestations. There are 5 types of lipedema which can be distinguished based on localization of fat deposits (12-16):

- Type I: increased deposit of fat in gluteus, hips and thighs

- Type II: lipedema extends to knees with a fat pad in the internal zone of the knees

- Type III: lipedema extends from hips to ankles

- Type IV: upper limbs are affected

- Type V: only the lower part of the legs is affected

Based on inspection and palpation, lipedema was also classified into 4 clinical stages of severity (12-16):

Stage 1: skin surface is normal and the subcutaneous fatty tissue has a soft consistency but multiple small nodules can be palpated.

Stage 2: skin surface is uneven and harder due to the increasing nodular structure (big nod- ules) of the subcutaneous fatty tissue (liposclerosis).

Stage 3: characterized by lobular deformation of the skin surface due to increased adipose tissue. The nodules vary in size and can be distinguished from the surrounding tissue on palpation. The phenomenon of "peau d'orange" can be seen by pressing the skin.

Stage 4: lipolymphedema. Subjective assessment included pain / discomfort scores using validated methods of assessment [Visual Analogue Scales (VAS)] for heaviness and numbness (17). The type of pain was also classified according to pathogenesis as neuropathic, nociceptive, or psychogenic. Neuropathic pain is pain caused by a lesion or disease of the somatosensory nervous system (18). Neuropathic pain is often associated with the sensation of burning, coldness, "pins and needles," numbness or itching. The pain may be spontaneous or evoked, as an increased response to a painful stimulus (hyperalgesia) or a painful response to a normally nonpainful stimulus (allodynia) (18). Patients typically experience a distinct set of symptoms, such as burning and electrical-like sensations, and pain resulting from non-painful stimulations (such as light touching); the symptoms persist and have a tendency to become chronic and respond less to pain medications (19).

Nociceptive pain is the most frequent type of pain, and it is the pain that arises from actual or threatened damage to non-neural tissue and is due to the activation of superficial or deep nociceptors (skin, musculoskeletal, vasa, etc.). Nociceptive pain may also be classified according to the site of origin and divided into "visceral," "deep somatic," and "superficial somatic" pain (20). Depending on the course, it can be classified into continuous or episodes of acute pain, the continuous being that which is persistent throughout the day and does not disappear, and the acute pain being the transitory exacerbation of pain. Depending on the intensity, pain can be mild when the patient performs normal activities, moderate when it interferes with normal activities and requires treatment with minor opioids, and severe when it interferes with rest 
and requires major opioids.

The second objective of the study was to assess orthopedic alterations including cavus or flat feet, knee misalignment valgus or varus knees, and knee osteoarthritis (OA) that was measured by radiologic assessment according to Kellgren $(21,22)$. Radiograph results included anteroposterior and lateral views of the knees with weight-bearing and foot map positioning. These were read by a bone and joint radiologist for radiographic knee OA using Kellgren-Lawrence Radiographic Grading Scale (KL), the most commonly used measures in epidemiologic studies of radiographic knee OA (23). This scale has been demonstrated to have high intrarater and interrater reliability (23), is highly correlated with knee pain (24), and is the recommended standard for population-based studies of radiographic knee OA (24).

Kellgren-Lawrence system is a validated method of classifying individual joints into one of five grades, from 0 representing normal and 4 being the most severe radiographic disease. This classification is based on features of osteophytes (bony growths adjacent to the joint space), narrowing of part or all of the tibial-femoral joint space, and sclerosis of the subchondral bone. A KL scale grade of $\geq 2$ indicates the presence of at least mild radiographic OA.

\section{Statistical Methods}

Descriptive statistics were obtained for all variables. For continuous variables, mean, standard deviation (SD) and median are presented, and for categorical variables absolute and relative frequencies were obtained. Qualitative variables were compared with the chisquare test and continuous variables with the analysis of variance (ANOVA). All statistical analyses were performed with IBM SPSS version 22.

\section{RESULTS}

\section{Sample Characteristics}

From September 2012 to December 2019, 138 patients met the inclusion criteria and were included in the study. The median of age was 47.6 years. The demographic and clinical characteristics of the patients are reported in Table 1. The mean of BMI was $29.9 \mathrm{Kg} / \mathrm{m}^{2}$, and $23.2 \%$ of the patients had a normal BMI, $31.2 \%$ were overweight, $37.7 \%$ were obese, and $8 \%$ had morbid obesity. Using the waist-toheight ratio, $41.3 \%$ of the patients were slim or healthy; $19.6 \%$ were overweight, and $36.1 \%$ were obese or morbid obese (Table 1).

The most frequent type of lipedema was Type III, which presents from the ankles to the hips and was found in two thirds of the patients. The majority of patients were in stage 1 and 2 (Fig. 1). Time elapsed from the reported onset of the symptoms until diagnosis was more than 25 years. Family history was present in $85 \%$ of the patients with a mean of 1.1 first degree members (95\%CI: 0.9-1.3) and 1.3 second degree members (95\% CI: 1.0-1.5). The onset of the symptoms was related to puberty in $57 \%$ of the patients (Table 1).

The greater the age, the more advanced stage of lipedema was found: stage 1 (mean age: 38.0 CI95\%: $34.7-41.3$ ); stage 2 (mean age: 48.8 CI95\%: 45.0-52.6); stage 3 (mean age: 58.1 CI95\%: 53.6-62.6); and stage 4 (mean age: 56.0 CI95\%: 49.5-62.5) $(\mathrm{p}<0.0001)$. The Waist-to-hip Index increased with the age $(\beta$ : $0.003(0.002-0.004) ; p<0.0001)$, losing the typical disproportion of lipedema phenotype.

Also, the greater the BMI, the more advanced stage of lipedema was found: stage 1 (mean of BMI; CI95\%) 25.5 (24.4-26.6); stage 2: 30.3 (28.7-32.0); stage 3: 34.5 (32.5-36.5); and stage 4: $38.8(34.1-43.6)(\mathrm{p}<0.001)$.

\section{Clinical Manifestations}

The most frequent features of lipedema with a prevalence above $80 \%$ were: symmetrical involvement of the lower limbs; unaffected feet; pain; easy bruising; vascular spiders; and disproportion between the upper and lower parts of the body (Table 2).

Pain was present in $92 \%$ and was nociceptive somatic in 80 cases $(60.2 \%)$ and neuropathic in $44(33.1 \%)$. The VAS score was 5.7 (95\% CI: 5.2-6.3). Pain was reported to be as episodes of acute pain in $67.7 \%$ and contin- 


\begin{tabular}{|c|c|}
\hline \multicolumn{2}{|c|}{$\begin{array}{c}\text { TABLE } 1 \\
\text { Description of the Study Population }\end{array}$} \\
\hline Patients & $(n=138)$ \\
\hline Age (median; Range) & $47.6(18-80.7)$ \\
\hline Age at the onset (median; Range) & $14.8(4-60)$ \\
\hline BMI (mean; 95\%CI) & $29.9(28.8-30.9)$ \\
\hline $\begin{array}{l}\text { BMI classification }(\mathrm{n} ; \%) \\
\text { Normal }\left(18.5-25 \mathrm{~kg} / \mathrm{m}^{2}\right) \\
\text { Overweight }\left(25-30 \mathrm{~kg} / \mathrm{m}^{2}\right) \\
\text { Obese Class I }(\text { Moderately obese })\left(30-35 \mathrm{~kg} / \mathrm{m}^{2}\right) \\
\text { Obese Class II (Severely obese) }\left(35-40 \mathrm{~kg} / \mathrm{m}^{2}\right)\end{array}$ & $\begin{array}{l}32(23.2 \%) \\
43(31.2 \%) \\
52(37.7 \%) \\
11(8 \%)\end{array}$ \\
\hline $\begin{array}{l}\text { Waist-to-Height ratio classification }(\mathrm{n} ; \%) \\
\text { Slim }(0.35-0.41) \\
\text { Healthy }(0.42-0.48) \\
\text { Overweight }(0.49-0.53) \\
\text { Very Overweight }(0.53-0.57) \\
\text { Obese }(>0.58) \\
\end{array}$ & $\begin{array}{l}14(10.1 \%) \\
43(31.2 \%) \\
27(19.6 \%) \\
22(15.9 \%) \\
32(23.2 \%) \\
\end{array}$ \\
\hline Time elapsed until diagnosis (mean; 95\%CI) & $25.5(25.0-27.9)$ \\
\hline $\begin{array}{l}\text { Type of lipedema }(\mathrm{n} ; \%): \\
\text { I: } \\
\text { II: } \\
\text { III: } \\
\text { IV: } \\
\text { V } \\
\end{array}$ & $\begin{array}{l}2(1.4 \%) \\
19(13.8 \%) \\
98(71 \%) \\
16(11.6 \%) \\
3(2.2 \%) \\
\end{array}$ \\
\hline $\begin{array}{l}\text { Stage of lipedema }(\mathrm{n} ; \%): \\
\text { 1: } \\
2: \\
3: \\
4: \\
\end{array}$ & $\begin{array}{c}52(37.7 \%) \\
48(34.8 \%) \\
31(22.5 \%) \\
7(5.1 \%) \\
\end{array}$ \\
\hline $\begin{array}{l}\text { Basal Volume in mL (mean; 95\%CI) } \\
\text { Right leg } \\
\text { Left leg }\end{array}$ & $\begin{array}{l}11,834(11,352-12,316) \\
11,690(11,213-12,166)\end{array}$ \\
\hline Waist-to-hip Index (mean; 95\%CI) & $0.71(0.69-0.72)$ \\
\hline Family history of edema & $116 / 137(84.7 \%)$ \\
\hline $\begin{array}{l}\text { Triggering factors (n; \%) } \\
\text { Not identified } \\
\text { Puberty } \\
\text { Pregnancy } \\
\text { Menopause } \\
\text { Contraceptives } \\
\end{array}$ & $\begin{array}{l}28(20.3 \%) \\
79(57.2 \%) \\
20(14.5 \%) \\
8(5.8 \%) \\
3(2.2 \%)\end{array}$ \\
\hline
\end{tabular}




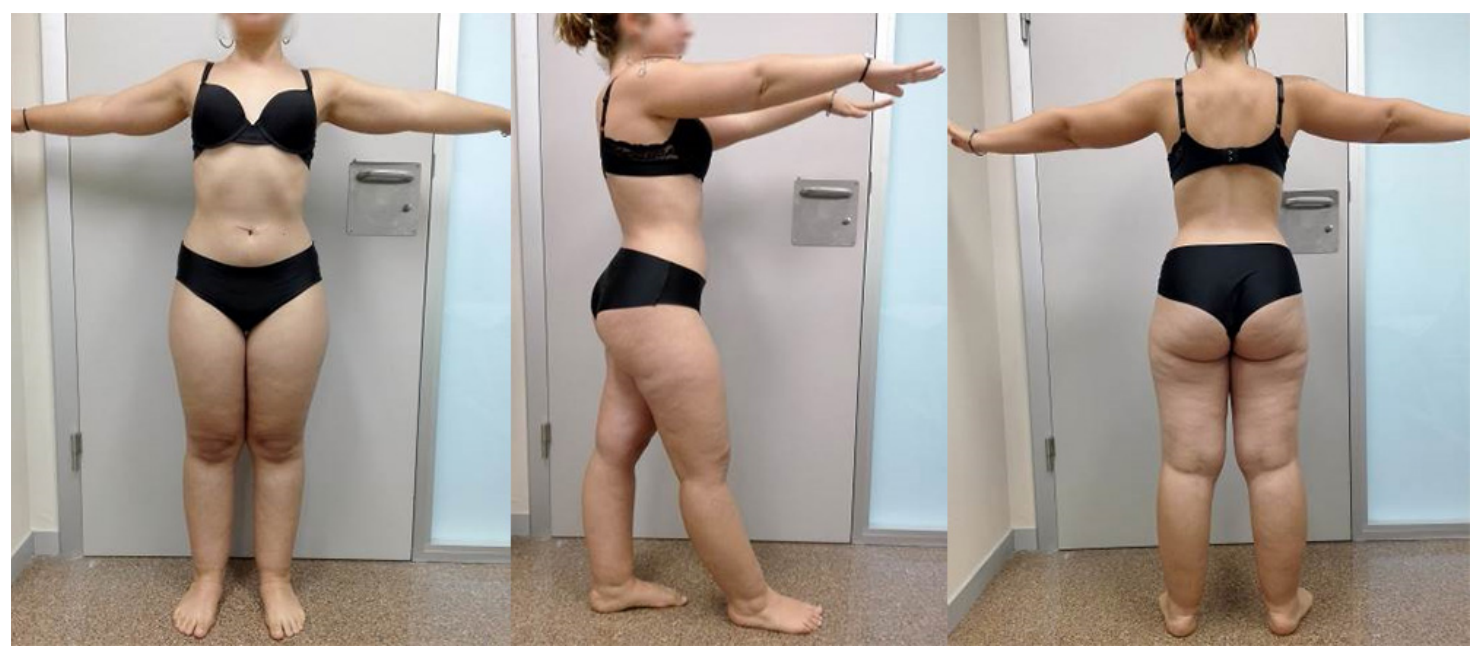

Fig. 1. A 22 year-old woman with type III lipedema and normal BMI in front, side, and back view.

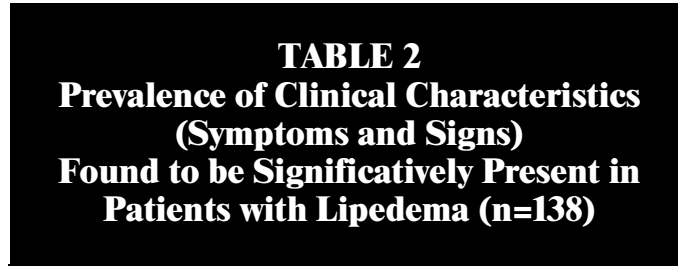

\begin{tabular}{|l|c|}
\hline Sign or Symptom & n (\%) \\
\hline Symmetrical involvement & $138(100 \%)$ \\
\hline Spare feet & $129(93.5 \%)$ \\
\hline Pain & $127(92 \%)$ \\
\hline Bruising & $125(90.6 \%)$ \\
\hline Vascular spiders & $124(89.9 \%)$ \\
\hline Disproportion & $119(86.2 \%)$ \\
\hline Cold skin & $59(42.8 \%)$ \\
\hline Venous insufficiency & $43(31.2 \%)$ \\
\hline Upper limbs involvement & $21(15.2 \%)$ \\
\hline Pitting sign & $20(14.5 \%)$ \\
\hline Stemmer Sign & $19(13.8 \%)$ \\
\hline Fibrosis & $9(6.5 \%)$ \\
\hline Lymphangitis attacks & $4(2.9 \%)$ \\
\hline
\end{tabular}

uous in $32.3 \%$. In $37.9 \%$ of the cases, pain was the cause to reduce social or working activities. Pain intensity measured by VAS was not associated to the stage of lipedema $(\mathrm{p}=0.072)$. In stages 1 and 2 , nociceptive somatic pain was the most frequent type of pain, $70.6 \%$ and $55.6 \%$, respectively, and in stage 4 neuropathic pain was the most frequent $(83.3 \%)(\mathrm{p}<0.05)$. A linear association was observed between intensity of pain measured by its interference with normal activities and the stage of lipedema; pain was worse in more advanced stages $(\mathrm{p}<0.0001)$.

Subjective assessment of heaviness showed a mean of heaviness of $6.6(95 \% \mathrm{CI}$ : 6.3-7.0) and a mean of numbness of 3.0 (95\% CI: 2.4-3.5).

In more advanced stages of lipedema, Stemmer' sign was more frequently positive: stage $1(3.8 \%)$, stage $2(14.6 \%)$, stage 3 $(19.4 \%)$, stage $4(57.1 \%)(\mathrm{p}<0.0001)$.

\section{Orthopedic Alterations}

Clinical examination from the orthopedic point of view revealed that cavus feet or valgus knees were present in one-third of the patients (Table 3). Mechanical pain at the knees was reported by $63 \%$ of the patients. Xray study of the knees was performed in 63 


\begin{tabular}{|c|c|}
\hline \multicolumn{2}{|c|}{$\begin{array}{l}\text { TABLE } 3 \\
\text { Orthopedic Alterations Found in Patients with Lipedema (n=138) }\end{array}$} \\
\hline $\begin{array}{l}\text { Footprint (n: \%): } \\
\text { Normal } \\
\text { Cavus feet } \\
\text { Flat feet } \\
\end{array}$ & $\begin{array}{l}76(55.1 \%) \\
41(29.7 \%) \\
21(15.2 \%)\end{array}$ \\
\hline $\begin{array}{l}\text { Knees (tibiofemoral angle) (n: \%): } \\
\text { Normal } \\
\text { Valgus } \\
\text { Varus }\end{array}$ & $\begin{array}{l}79(57.2 \%) \\
54(39.1 \%) \\
5(3.6 \%)\end{array}$ \\
\hline Knee pain (n: \%) & $87(63 \%)$ \\
\hline Knee pain VAS (mean; 95\%CI) & $5.9(5.5-6.5)$ \\
\hline $\begin{array}{l}\text { Knee osteoarthritis (Kellgren-Lawrence Scale) }(\mathrm{n}=63)(\mathrm{n}: \%) \\
\text { No radiographic findings of osteoarthritis } \\
1 \text { Minute osteophytes of doubtful clinical significance } \\
2 \text { Definite osteophytes with unimpaired joint space } \\
3 \text { Definite osteophytes with moderate joint space narrowing } \\
4 \text { Definite osteophytes with severe joint space narrowing and subchondral sclerosis }\end{array}$ & $\begin{array}{l}8 / 63(12.7 \%) \\
18 / 63(28.6 \%) \\
16 / 63(25.4 \%) \\
15 / 63(23.8 \%) \\
6 / 63(9.5 \%)\end{array}$ \\
\hline
\end{tabular}

patients, and knee osteoarthritis (OA) was diagnosed in different stages of the disease.

Eighty-seven patients complained about knee pain, but $x$-ray was performed in only 63 of them for different reasons (some were followed by other doctors in another hospital).

Thirty-seven patients $(58.7 \%)$ had a knee $\mathrm{OA} \geq 2$ in $\mathrm{K}-\mathrm{L}$ scale. Knee OA was more severe in older patients $(\mathrm{p}<0.0001)$ and in patients with a higher $\mathrm{BMI}(\mathrm{p}<0.0001)$ and higher weight $(\mathrm{p}<0.0001)$. We observed a linear association between the degree of knee $\mathrm{OA}$ and the stage of lipedema, OA was more severe in more advanced patients $\left(X^{2}: 16.348 ; p<0.0001\right)$. No relationship was observed between knee $\mathrm{OA}$ and knee malalignment ( $\mathrm{p}=\mathbf{0 . 0 6 5})$.

\section{DISCUSSION}

Despite the fact that research in lipedema is increasing, we found few papers reporting data about descriptive data of lipedema population that could give us a reference for comparison among countries.

Concerning lipedema types, Type III (affecting from ankles to hips) was the most frequent in our sample. This could be explained by a bias in the selection of the recruited patients, because this type is easier to differentiate from obesity for medical staff. Another reason that needs further investigation in the future is that Type III could be the most frequent type in the Spanish population.

We observed that most of our patients had a stage 1 and 2 lipedema. The selection bias can explain this too. In advanced and very chronic stages, patients are difficult to diagnose with a pure lipedema, and patients with a suspicion of associated lymphedema or obesity-induced lymphedema were excluded from the study. Herbst describes a sample with 50 patients where stage 2 is predominant (25).

In our sample, diagnosis of lipedema was performed very late after the onset of the symptoms (approximately 25.5 years) due to unawareness and lack of knowledge among professionals. This provokes anxiety among patients and difficulties in starting the management of lipedema.

Regarding the most frequent comorbidity in lipedema that is obesity, our data differ from other authors' results. The mean of BMI was 
$29.9 \mathrm{Kg} / \mathrm{m}^{2}$, lower than in the study of Herbst $\left(38 \mathrm{~kg} / \mathrm{m}^{2}\right)(25)$. Only $45.7 \%$ of our patients were obese (BMI $\left.>30 \mathrm{~kg} / \mathrm{m}^{2}\right)$ that is clearly different from the $88 \%$ reported by Bertsch (26) or the $76 \%$ reported by Herbst (25).

To assess the nutritional status of the patients, we accepted the recommendation of Bertsch that, the waist-to-height ratio (WHtR) is the more appropriate measure for lipedema patients. The WHtR describes the ratio between waist circumference and height and is a better indicator of body fat distribution (27). Analyzing the waist-to-height ratio, $41.3 \%$ of the patients of our study, were slim or healthy; $19.6 \%$ were overweight and $36.1 \%$ were obese or morbid obese. With the waist-to-height ratio distribution (Table 2), it is important to note that the lipedema population is very different from the German one described by Bertsch, where normal weight is a rarity (26). Among our patients, there were $41 \%$ with normal weight, and maybe we can consider these as pure lipedema patients, without the involvement of obesity that leads to lymphedema.

We observed that the more advanced stages of lipedema were more frequent among older patients, and this could suggest the progressive characteristic of lipedema. This is controversial as many authors state that lipedema is not progressive along time (27). Large variability in the natural history of lipedema is noted. While some patients develop only mild lipedema, which does not progress with the time, others show gradual and slow progression $(28,29)$. This point should be further investigated.

Obesity was also related to more advanced stages of lipedema in our study. According to Bertsch, there is no evidence that lipedema leads to weight gain, but in fact, weight gain is a trigger factor for the onset and maybe the progression to more advanced stages of lipedema $(26,29,30)$. Further investigation is needed to clear up this association in order to improve the management of the patients.

The high percentage of family history of lipedema in this series $(85 \%)$ can be explained by the bias of selection of patients. Many of them bring up their family members to the
Unit because they find it difficult to get specialized medical assistance in other places. To improve the management of lipedema, it is important to increase awareness among professionals. Nevertheless, lipedema is thought to be an inherited disease in most cases with a positive family history of lipedema in $64 \%$ of women, therefore, a genetic etiology for lipedema is strongly suggested (31). Several genetic factors have been related to the onset of lipedema. No genetic tests or guidelines for molecular diagnosis of lipedema are currently available despite the fact that genetic testing is fundamental for the differential diagnosis of lipedema against Mendelian genetic obesity, primary lymphedema, and lipodystrophies (32). A recent study has reported a variant in Aldo-Keto Reductase $1 \mathrm{C} 1$ in a family with non-syndromic lipedema (33).

More than half of the patients in our study reported an onset of the symptoms at puberty. This observation together with adipose tissue enlargement localization brings up the presumptive sex hormonal influence of lipedema adipogenesis (34).

The most frequent features of lipedema with a prevalence above $80 \%$ were: symmetrical involvement of the lower limbs; unaffected feet; pain; easy bruising; vascular spiders; and disproportion between the upper and lower parts of the body. These could be considered as Major criteria for diagnosis and have been included in the Dutch guidelines (13). The rest of the features are more typical from lymphedema and they can be useful for differential diagnosis. Clinically, disproportion between the upper and lower part of the body is very specific for lipedema but may not be present in all the patients because this feature is lost with obesity as Dietzel observed (35).

As well as in other studies, pain was a frequent manifestation in our sample (25). Although it is a common feature, and for some it is the leading complaint (36), not many publications have been devoted to deeply analyze this symptom. Neurological mechanism, mechanical forces and biochemical factors derived from inflammation have been suggested as etiopathogenical factors for pain (37). A recent study states that pain in lipedema is 
attributed to allodynia, exaggerated sympathetic signaling, and estrogens (38). Pain affects significantly quality of life $(36,39)$. Angst et al have shown a high correlation between the changes in pain and depression levels in a cohort of lipedema patients, suggesting that relieving pain may lead to the relief of depression and vice versa (40). We observed that pain interference in normal activities was related to the stage of lipedema, whereas other authors did not find this association (38). As it can be disabling in one third of the patients with the complaint that pain is impairing their social and working activities, we should address our efforts to manage it and not to forget or to minimize its importance in quality of life. Clinical examination from the orthopedic point of view is important to have a whole evaluation of the patient and to complete the integrative and multidisciplinary management of lipedema patients. Knee pain was frequent, and this can impair the ability to do sports or even to walk, therefore making it more difficult to lose weight and comply with the exercise recommendation. The relation between obesity and pain in the knees has been reported (41). For some authors, the orthopedic disorders can be caused by the increased lower extremities weight that may lead to joint damage, gait alternations, impaired mobility (29), and an alteration in the gait pattern as in lymphedema patients (42). Knee OA can be a cause, but muscular weakness due to lack of physical activity can worsen it.

The prevalence of knee osteoarthritis (OA) is increasing worldwide, and the burden of the disease in terms of disability will rise (43). Its negative impact in people's physical and mental well-being and costs of the management cannot be ignored (44). Only 63 patients underwent $\mathrm{x}$-ray to detect knee $\mathrm{OA}$, so the prevalence was biased. One of the reasons is that in younger aged patients we tried to avoid radiation to the patient only for research and other patients did not consent to undergo $\mathrm{x}$-ray as they were being treated in their reference center. Knee OA was diagnosed in different stages of the disease in 37 cases (58.7\%) using the Kellgren-Lawrence scale (KL). The first two grades in this scale are defined exclu- sively by the presence of osteophytes. For this reason, a patient with joint space narrowing but no associated osteophytes cannot be classified as having $\mathrm{OA}$ according to the KL system. Patients with no radiographic findings of $\mathrm{OA}$ can present significant articular cartilage degeneration (45), so probably the prevalence of OA is higher than our study shows.

The reported prevalence of symptomatic knee OA is $15.2 \%$ (46). According to a recent study (EPISER2016), the prevalence of knee OA in Spain was $13.83 \%$ (47) and was related to overweight and obesity. In our sample, the frequency of OA (37/63) was high, so it is important to avoid the detrimental effect in patients' mobility and function. For knee OA, strong evidence indicates that obesity is a strong risk factor (43) and knee malalignment is a strong predictor of knee OA disease progression $(43,44)$. The last association was not observed in our study.

This study identified an association between OA and the stage of lipedema. Other than the weight, different pathophysiological mechanisms that could be implied in both diseases and this should be investigated in future research.

As exercise therapy has shown to be effective in decreasing pain and improving joint motion in knee OA, a program of strengthening and general aerobic exercises is highly recommended in these patients as well as trying to improve their adherence to it at longterm (43).

The management of lipedema patients involves a precise diagnosis and Physical Medicine and Rehabilitation can be of help. Cavus feet can be corrected with custom-made foot orthotics that are effective for treating foot pain (48). Another benefit of the orthotics could be to improve the pressure to the vascular system at the sole during the stance phase of the walk.

\section{CONCLUSIONS}

In our sample, the most frequent type of lipedema identified was type III and in stages 1 and 2 . The features that should be considered as major criteria for diagnosis are: sym- 
metrical involvement of the lower limbs; unaffected feet; pain; easy bruising; vascular spiders; and disproportion between the upper and lower parts of the body. Despite the reported relation with obesity, more than a third of the patients of our study were not overweighed. Orthopedic examination is important to detect knee misalignment and knee OA that contribute to patient's impairment and should be considered in further research.

\section{CONFLICT OF INTEREST AND DISCLOSURE}

The authors declare no competing financial interests exist. No funding was received for this study.

\section{REFERENCES}

1. Allen, EV, EA Hines: Lipedema of the legs: A syndrome characterized by fat legs and orthostatic edema. Proc. Staff Meet Mayo Clin. 15 (1940), 184-187.

2. Fife, CE, EA Maus, MJ Carter: Lipedema: A frequently misdiagnosed and misunderstood fatty deposition syndrome. Adv. Skin Wound Care 23 (2010), 81-92.

3. Földi, E, M Földi: Lipedema. In: Földi's Textbook of Lymphology. Földi M, Földi E (Eds). Munich, Germany: Elsevier GmbH; 2006:417-427.

4. Forner-Cordero, I, G Szolnoky, A FornerCordero, L Kemény: Lipedema: An overview of its clinical manifestations, diagnosis and treatment of the disproportional fatty deposition syndrome - systematic review. Clin. Obesity 2 (2012), 86-95.

5. Schmeller, W, I Meier-Vollrath: Lipödem: Ein update. [Lipedema: an update.] Lymphol. Forsch. Prax. 9 (2005), 10-20.

6. Greene, A, P Meskell: The impact of lower limb chronic oedema on patients' quality of life. Int. Wound J. 14 (2017), 561-568. doi: 10.1111/iwj.12648.

7. World Health Organization, International Statistical Classification of Diseases and Related Health Problems 11th Revision. [WWW document]. URL https://icd.who.int/browse11/1m/en\#/http://id.who.int/icd/entity/1172950828.

8. Buso, G, M Depairon, E Tomson, et al: Lipedema: A call to action! Obesity (Silver
Spring). 29 (2019), 1567-1576. doi: 10.1002/oby.22597.

9. Wold, LE, EA Hines Jr, EVeAllen: Lipedema of the legs: A syndrome characterized by fat legs and edema. Ann. Intern. Med. 34 (1951), 1243-1250.

10. Herbst, KL: Rare adipose disorders (RADs) masquerading as obesity. Acta Pharmacol. Sin. 33 (2012), 155-172.

11. Kurz, I: Textbook of Dr. Vodder's manual lymph drainage. In: Therapy. 2nd ed., Harris, RS (Ed). Heidelberg (Germany): Karl S. Haug Publishers; 1989.

12. Schmeller, W, I Meier-Vollrath: Das Lipodem: neue Möglichkeiten der Therapie. Schweiz Med. Forum. 7 (2007), 150-155.

13. Halk, AB, RJ Damstra: First Dutch guidelines on lipedema using the international classification of functioning, disability and health. Phlebology 32 (2017), 152-159. doi:10.1177/0268355516639421

14. Lontok, E, L Briggs, M Donlan, et al: Lipedema. A giving smarter guide. Milken Inst. Strategic Philanthropy, 2017.

15. Wounds UK. Best Practice Guidelines: The Management of Lipoedema. London: Wounds UK, 2017.

16. Dayan, E, JN Kim, ML Smith: Lipedema The disease they call FAT: An overview for clinicians. Boston, MA: Lipedema Simplified Publications, The Friedman Center for Lymphedema Research and Treatment at The Center for Advanced Medicine at Northwell Health in collaboration with Lymphatic Education \& Research Network (LE\&RN); 2017.

17. Rönkä, R, K von Smitten, $\mathbf{T}$ Tasmuth, $\mathbf{M}$ Leidenius: One-year morbidity after sentinel node biopsy and breast surgery. Breast. 14 (2005), 28-36.

18. Scholz, J, NB Finnerup, N Attal, et al: The IASP classification of chronic pain for ICD11: Chronic neuropathic pain. Pain 160 (2019), 53-59. doi: 10.1097/j.pain.0000000000001365.

19. Colloca, L, T Ludman, D Bouhassira, et al: Neuropathic pain. Nat. Rev. Dis. Primers 16 (2017), 3. 17002. doi: 10.1038/nrdp.2017.2.

20. Urch, CE, R Suzuki: Pathophysiology of somatic, visceral, and neuropathic cancer pain. In: Clinical Pain Management: Cancer Pain ( 2 ed.). Sykes N, Bennett MI \& Yuan CS (Eds). London: Hodder Arnold. pp. 3-12.

21. Kellgren, JH, JS Lawrence: Radiological assessment of osteo-arthrosis. Ann. Rheum. 
Dis. 16 (1957), 494-502.

22. Kellgren, JH, M Jeffrey, J Ball: Atlas of Standard Radiographs. Oxford: Blackwell Scientific, 1963.

23. Spector, TD, DJ Hart, J Byrne, et al: Definition of osteoarthritis of the knee for epidemiological studies. Ann. Rheum. Dis. 52 (1993), 790-794.

24. Lethbridge-Cejku, M, WW Scott Jr, R Reichle, et al: Association of radiographic features of osteoarthritis of the knee with knee pain: Data from the Baltimore Longitudinal Study of Aging. Arthritis Care Res. 8 (1995), 182-188.

25. Herbst, KL, L Mirkovskaya, A Bharhagava, et al: Lipedema fat and signs and symptoms of illness, increase with advancing stage. Arch. Med. 7 (2015), 1-8.

26. Bertsch, T, G Erbacher: Lipoedema - myths and facts Part 3. Phlebologie 47 (2018), 188-197.

27. Bertsch, T, G Erbacher: Lipoedema - myths and facts Part 1. Phlebologie 47 (2018), 84-92. DOI: $10.12687 /$ phleb2411-2-2018

28. Langendoen, SI, L Habbema, TE Nijsten, HA Neumann: Lipoedema: From clinical presentation to therapy. A review of the literature. Br. J. Dermatol. 161 (2009), 980-986.

29. Lyszczak, P, A Szuba: Lipedema: A clinical entity. Acta Angiol. 24 (2018), 141-148. doi: 10.5603/AA.2018.0020

30. Fife, C, M Carter: Lymphoedema in bariatric patients. J. Lymphoedema 4 (2009), 29.

31. Child, AH, KD Gordon, P Sharpe, et al: Lipedema: An inherited condition. Am. J. Med. Genet. A. 152A (2010), 970-976.

32. Paolacci, S, V Precone, F Acquaviva, et al: Genetics of lipedema: New perspectives on genetic research and molecular diagnoses. Eur. Rev. Med. Pharmacol. Sci. 23 (2019), 5581-5594.

33. Michelini, S, P Chiurazzi, V Marino, et al: Aldo-Keto Reductase 1C1 (AKR1C1) as the first mutated gene in a family with nonsyndromic primary lipedema. Int. J. Mol. Sci. 21 (2020), 6264. doi: 10.3390/ijms21176264.

34. Szél, E, L Kemény, G Groma, G Szolnoky: Pathophysiological dilemmas of lipedema. Med. Hypotheses 83 (2014), 599-606.

35. Dietzel, R, A Reisshauer, S Jahr, et al: Body composition in lipoedema of the legs using dual-energy X-ray absorptiometry: A case- control study. Br. J. Dermatol. 173 (2015), 594-596. doi: 10.1111/bjd.13697.

36. Wollina, U: Lipedema - An update. Dermatol. Ther. 32 (2019), :e12805.

37. Kruppa, P, I Georgiou, N Biermann, et al: Lipedema-pathogenesis, diagnosis and treatment options. Dtsch. Arztebl. Int. 117 (2020), 396-403. DOI: 10.3238/arztebl.2020.0396

38. Aksoy, H, AS Karadag, U Wollina: Cause and management of lipedema-associated pain. Dermatol. Ther. Oct 1 (2020), e14364. Epub ahead of print. doi: 10.1111/dth.14364

39. Romeijn, JRM, MJM de Rooij, L Janssen, H Martens: Exploration of patient characteristics and quality of life in patients with lipoedema using a survey. Dermatol. Ther. (Heidelb). 8 (2018), 303- 311.

40. Angst F, Benz T, Lehmann S, et al. Extended overview of the longitudinal pain-depression association: A comparison of six cohorts treated for specific chronic pain conditions. J Affect Disord. 2020; 273: 508-516. doi: 10.1016/j.jad.2020.05.044.

41. Adamson, J, S Ebrahim, P Dieppe, K Hunt: Prevalence and risk factors for joint pain among men and women in the West of Scotland Twenty-07 study. Ann. Rheum. Dis. 65 (2006), 520-524.

doi:10.1136/ard.2005.037317

42. Forner-Cordero, I, F Furtado, J CerveraDeval, et al: Ground reaction force patterns during gait in patients with lower limb lymphedema. Acta Fisiátr. 23 (2016), 201-207.

43. Hunter, DJ, S Bierma-Zeinstra: Osteoarthritis. Lancet 393 (2019), 1745-1759. doi: 10.1016/S0140-6736(19)30417-9.

44. Vina, ER, CK Kwoh: Epidemiology of osteoarthritis: Literature update. Curr. Opin. Rheumatol. 30 (2018), 160-167. doi: 10.1097/ BOR.0000000000000479.

45. Kijowski, R, D Blankenbaker, P Stanton, et al: Arthroscopic validation of radiographic grading scales of osteoarthritis of the tibiofemoral joint. Am. J. Roentgenol. 187 (2006), 794-799. doi:10.2214/AJR.05.1123

46. Murphy, L, TA Schwartz, CG Helmick, et al: Lifetime risk of symptomatic knee osteoarthritis. Arthritis Rheum. 59 (2008), 1207-1213. doi: 10.1002/art.24021.

47. Blanco, FJ, M Silva-Díaz, V Quevedo Vila, et al: Prevalence of symptomatic osteoarthritis 
in Spain: EPISER2016 study. Reumatol. Clin. S1699-258X (2020), 30023-1. doi:10.1016/j.reuma.2020.01.008.

48. Burns, J, KB Landorf, MM Ryan, et al: Interventions for the prevention and treatment of pes cavus. Cochrane Database Syst. Rev. Oct 17 (2007), CD006154. doi:10.1002/14651858.CD006154.pub2
Isabel Forner-Cordero, MD, PhD Lymphedema Unit, Physical Medicine and Rehabilitation Service

Hospital Universitari i Politècnic La Fe, Avenida de Fernando Abril Martorell, no 106 46026 Valencia, Spain

Telephone: 961244000, Ext. 411157

Email: ifornercordero@gmail.com

Secondary email: forner_isa@gva.es 